\title{
Keputusan Pemilihan Karier: Studi Komparatif pada Siswa Remaja Jurusan IPA dan IPS
}

\author{
Fatma Nur Aqmarina, Erna Risnawati \\ Universitas Mercu Buana, Jl. Raya Kembangan No. 1 Kembangan Jakarta Barat 11650 \\ e-mail: pinksyauqi@gmail.com
}

\begin{abstract}
The purpose of this study was to compare career choice decisions between students majoring in Science and Social Sciences. This study used the comparative quantitative method. The subjects were 188 students, consists of 94 students on each major in Science and Social Science. The subjects were selected by purposive sampling, with the characteristics of class XII students majoring in science and social studies and aged 15-18 years. The data were analyzed using Mann-Whitney Nonparametric Test. The findings showed that there were no significant differences in career choice decisions between students majoring in Science and Social Sciences. There were 39 science and 53 social sciences students who have difficulties in deciding their careers.
\end{abstract}

Keywords: career, career choice decisions, career choice

\begin{abstract}
Abstrak
Tujuan penelitian ini untuk membandingkan keputusan pemilihan karier antara siswa jurusan IPA dan IPS. Metode dalam penelitian ini menggunakan metode kuantitatif komparatif. Subjek dalam penelitian ini berjumlah 188 siswa, dengan jumlah yang seimbang antara siswa jurusan IPA dan IPS yaitu masing-masing 94 siswa. Subjek dipilih dengan purposive sampling yaitu pemilihan subjek disesuaikan pada karakteristik yang telah peneliti tentukan yaitu siswa kelas XII jurusan IPA maupun IPS dan berusia 15-18 tahun. Analisa data dalam penelitian ini menggunakan Uji Nonparametrik Mann-Whitney diperoleh hasil bahwa tidak ada perbedaan yang signifikan dari keputusan pemilihan karier antara siswa jurusan IPA dan IPS. Terdapat 39 siswa jurusan IPA dan 53 siswa jurusan IPS yang mengalami kesulitan dalam mengambil keputusan pemilihan karier.
\end{abstract}

Kata Kunci: karier, keputusan pemilihan karier, pemilihan karier

\section{Pendahuluan}

Siswa kelas XII SMA mengalami kendala dalam memutuskan pilihan karier mereka. Hal ini didukung dengan data survei yang dilakukan oleh Aqmarina, Sahrani, dan Hastuti (2017) kepada siswa kelas XII di Madrasah Aliyah Negeri (MAN) Y Jakarta bahwa kebimbangan siswa kelas XII diantaranya ragu dengan pilihannya, merasa banyak saingan untuk masuk perguruan tinggi dan ketakutan nilai akademik yang dimiliki tidak mencukupi untuk pilihan jurusan yang diminati. Kondisi tersebut sejalan dengan yang dialami oleh siswa kelas XII di MAN B Jakarta. Selain itu, kondisi siswa kelas XII MAN B Jakarta ada pula siswa yang masuk jurusan IPS karena nilai mereka yang kurang mencukupi untuk masuk jurusan IPA. Hal ini menyebabkan kebimbangan dan konflik dalam diri siswa karena jurusan yang ia tekuni saat ini tidak sejalan dengan jurusan yang diinginkannya.

Fenomena tersebut berkaitan dengan keputusan pemilihan karier yang kurang baik. Keputusan pemilihan karier merupakan proses individu memahami dirinya dan dunia pekerjaan serta kemampuan mengintegrasikan antara dirinya dengan pekerjaannya (Parsons dalam Creed, Wong, \& Hood, 2009).

Sejalan dengan penelitian sebelumnya yang dilakukan oleh Allolayuk, Setiawan, dan Dimyati (2013) bahwa siswa SMA jurusan IPA $81.58 \%$ memilih jurusan IPA 
karena faktor bakat yang dimilikinya sedangkan $73.68 \%$ dipengaruhi oleh faktor eksternal yaitu pendidik di sekolah. Dapat disimpulkan bahwa faktor bakat pada pelajaran IPA merupakan faktor dominan bagi siswa memilih jurusan IPA di sekolah. Sedangkan penelitian yang dilakukan oleh Aria (2011) mengatakan bahwa faktor internal berupa minat dominan memengaruhi siswa jurusan IPS memilih jurusan IPS $(16.81 \%)$.

Setiap individu tentunya perlu membuat keputusan tentang kariernya (career decision-making). Karier merupakan suatu peran yang khas yang diperankan oleh individu yang dibentuk berdasarkan sesuatu yang dipilih dan tidak dipilih oleh individu tersebut (Herr \& Crammer dalam Brown, 2012). Peran tersebut dipilih oleh individu dengan berbagai macam pertimbangan berdasarkan pengalaman yang individu alami. Seorang individu sering mengalami kesulitan untuk memutuskan peran khas yang akan ia pilih seumur hidupnya.

Saat anak tumbuh menjadi remaja, mereka memiliki tugas perkembangan untuk menentukan karier yang akan ditekuni kelak (Papalia, 2015) Menurut Piaget (dalam Santrock, 2014), remaja usia 11 tahun hingga dewasa sudah mampu untuk melakukan idealisasi serta membayangkan kemungkinankemungkinan tentang solusi masalah yang mereka hadapi. Sehingga seharusnya mereka sudah mampu melakukan hipotesis (dugaan terbaik) serta merencanakan masa depan mereka salah satunya yaitu melakukan spekulasi dengan memperkirakan jurusan apa yang hendak mereka pilih setelah lulus SMA. Pada remaja siswa sekolah menengah akhir terutama kelas XII erat kaitannya dengan keputusan pemilihan karier (Bloxom, Bernes, Magnusson, Gunn, Bardick, Orr, \& McKnight, 2008).

Hal lainnya yang membuat remaja sulit mengambil keputusan seperti kurangnya informasi mengenai dunia kerja. Berdasarkan penelitian yang dilakukan oleh Creed dkk. (2009) bahwa kurangnya informasi mengenai dunia kerja menjadi kendala bagi siswa untuk menentukan karier mereka. Selama anak sekolah, mereka hanya mengetahui bahwa tugas mereka adalah belajar dengan sebaik-baiknya namun mereka tidak mengetahui untuk apa gunanya mereka belajar dengan sungguhsungguh untuk kehidupan mereka kelak. Siswa remaja kurang diberikan informasi tentang dunia kerja tertentu kemudian keterampilan apa yang harus mereka miliki untuk dapat menekuni pekerjaan tersebut kelak sehingga mereka dapat mempersiapkan diri mereka sejak dini dengan sungguhsungguh.

Creed dkk. (2009) juga mengatakan bahwa wawasan yang minim tentang program studi serta pengetahuan yang terbatas tentang jurusan yang tersedia di perguruan tinggi juga menghambat siswa remaja untuk memutuskan pilihan karier. Kurangnya informasi pengetahuan dan wawasan remaja mengenai program studi, jurusan dan dunia kerja akan membuat remaja salah memilih jurusan sehingga berdampak negatif bagi karier mereka kelak.

Salah satu karakteristik partisipan yaitu berusia 15-18 tahun karena pada usia tersebut menurut Super (dalam Isaacson \& Brown, 2012; Brown, 2012; Zunker, 2014; Wendy \& Patton, 2014) partisipan berada pada masa remaja pertengahan yang berada pada tahap eksplorasi yaitu tahap individu membuat pilihan yang berhubungan dengan keputusan jurusan di perguruan tinggi.

Pada penelitian sebelumnya yang meneliti perbandingan siswa jurusan IPA dan IPS menyatakan bahwa terdapat perbedaan sikap, perilaku dan pola pikir pada siswa jurusan IPA dan IPS dalam belajar (Pratiwi, 2016). Sejalan dengan pemikiran tersebut peneliti menduga bahwa ada perbedaan juga antara keputusan pemilihan karier siswa jurusan IPA dan IPS karena sikap, perilaku dan pola pikir juga memengaruhi seseorang dalam memutuskan pilihan (Santrock, 2011). 
Dengan fenomena yang terjadi di MAN B Jakarta maka penelitian ini perlu dilakukan untuk membandingkan keputusan pemilihan karier antara siswa jurusan IPA dengan IPS. Dengan mengetahui adanya perbedaan keputusan pemilihan karier antara siswa jurusan IPA dan IPS dapat diberikan intervensi yang berbeda dalam mengatasi kebimbangan pemilihan karier. Peneliti menduga bahwa siswa jurusan IPA memiliki keputusan pemilihan karier yang lebih baik daripada siswa jurusan IPS.

\section{Keputusan Pemilihan Karier}

McDaniels (dalam Brown, 2012; Isaacson \& Brown, 1997) mengatakan bahwa peran individu dalam bekerja pada suatu pekerjaan dan kegiatan yang banyak dilakukan individu saat waktu luang merupakan dua peran yang tidak dapat dipisahkan dalam mendefinisikan karier, karier meliputi dua peran yang tidak dapat dipisahkan yaitu peran dalam bekerja dan peran dalam memanfaatkan waktu luang (leisure).

Sesuatu yang khas pada tiap-tiap individu dan dibentuk berdasarkan sesuatu yang dipilih dan tidak dipilih oleh individu merupakan karier oleh Herr dan Cramer (Brown, 2012; Isaacson \& Brown, 1997; Zunker, 2012; Patton \& McMahon, 2014).

Proses pengumpulan informasi mengenai alternatif-alternatif yang relevan dalam membuat pilihan dengan tepat merupakan definisi dari pengambilan keputusan atau decision-making (Noorderhaven, 1995). Pengambilan keputusan dilakukan setelah individu melakukan proses pengumpulan informasi sehingga memiliki berbagai alternatif untuk memutuskan suatu hal. Butler (dalam Soejono, 1990) mendefinisikan pengambilan keputusan sebagai aktivitas yang membutuhkan proses rasional. Aktivitas pengambilan keputusan harus dilakukan secara rasional agar tercapai keputusan yang tepat. Sedangkan, Santrock (2014) mendefinisikan pengambilan keputusan adalah pemikiran individu mengevaluasi berbagai pilihan dan memu- tuskan pilihan dari sekian banyak pilihan tersebut. Keputusan diambil setelah individu memertimbangkan dan mengevaluasi berbagai informasi yang dimiliki kemudian memilih satu pilihan dari berbagai pilihan yang ada.

Dapat disimpulkan bahwa keputusan pemilihan karier adalah proses individu memahami dirinya dan dunia pekerjaan serta kemampuan mengintegrasikan antara dirinya dengan pekerjaannya (Parsons dalam Creed dkk., 2009).

Untuk dapat mengukur kemampuan individu dalam melakukan keputusan pemilihan karier maka dibutuhkan sebuah alat ukur career decision scale yang dikembangkan oleh Osipow, Carney, Winer, Yanico, dan Koschier (1987) merupakan alat ukur yang dapat mengukur kemampuan individu dalam mengambil keputusan karier. Alat ukur ini melihat gambaran individu yang mampu mengambil keputusan karier ditunjukkan dengan perolehan skor yang rendah pada career decision scale sedangkan individu yang bimbang dalam mengambil keputusan karier ditunjukkan dengan perolehan skor tinggi pada career decision scale (Osipow dalam Brown, 2012).

\section{Tahap Perkembangan Karier}

Terdapat lima tahap perkembangan karier meliputi growth stage, exploration stage, establishment stage, maintenance stage dan decline stage (Super dalam Isaacson \& Brown, 1997; Brown, 2012; Zunker, 2014; Patton \& McMahon, 2014).

Tahap perkembangan karier yang pertama, growth stage, tahap ini berlangsung dari bayi sampai usia 14 tahun. Karakteristik dari tahap ini adalah penekanan pada perkembangan fisik dan psikologis. Selain itu, terbentuknya sikap, nilai, kemampuan dan keterampilan serta minat akan memengaruhi pikiran individu di masa yang akan datang. Tahap kedua, exploration stage, tahap ini berlangsung dari masa remaja sampai pertengahan usia 20 tahunan. Pada akhir masa remaja, individu akan mulai membuat pilihan yang 
berhubungan dengan pekerjaan di masa yang akan datang seperti membuat keputusan jurusan kuliah. Tahap yang ketiga, establishment stage, pada tahap ini merupakan tahap awal dari proses karier yang berlangsung sampai usia dewasa muda dimana individu mulai masuk dalam pekerjaannya. Kemudian tahap keempat, maintenance stage, yaitu usia paruh baya sekitar 45-65 tahun dan merupakan tahap mempertahankan posisi pekerjaan; dan kelima tahap decline stage, berlangsung pada usia lanjut, bagi kebanyakan individu merupakan tahap pensiun dari pekerjaannya dan adanya kebutuhan baru untuk mencari peran lain untuk mengekspresikan dirinya.

\section{Metode Penelitian}

\section{Desain Penelitian}

Desain penelitian yang digunakan adalah kuantitatif dengan metode komparatif (Sugiyono, 2018). Penelitian ini bertujuan untuk membandingkan keputusan pemilihan karier siswa kelas XII SMA jurusan IPA dan IPS.

\section{Partisipan Penelitian}

Partisipan dipilih dengan teknik purposive sampling yaitu berdasarkan karakteristik tertentu sesuai tujuan penelitian. Karakteristik partisipan pada penelitian ini meliputi: (a) siswa yang berusia 15-18 tahun, (b) siswa kelas XII jurusan IPA dan IPS pada tahun ajaran 2018-2019. Salah satu karakteristik partisipan yaitu siswa yang berusia 15-18 tahun karena pada usia tersebut partisipan berada pada tahap perkembangan karier eksplorasi yaitu tahap individu membuat pilihan yang berhubungan dengan keputusan pemilihan karier (Super dalam Isaacson \& Brown, 2012; Zunker, 2014; dan Patton \& McMahon, 2014). Sebaran jumlah siswa pada setiap jurusan disajikan pada tabel 1 .
Tabel 1

Jumlah Siswa Perkelas

\begin{tabular}{llll}
\hline \multicolumn{2}{l}{ Jurusan IPA } & \multicolumn{3}{l}{ Jurusan IPS } \\
\hline IPA 1 & 33 & IPS 1 & 34 \\
IPA 2 & 29 & IPS 2 & 31 \\
IPA 3 & 32 & IPS 3 & 29 \\
Total & 94 & Total & 94 \\
\hline
\end{tabular}

\section{Instrumen Penelitian}

Alat ukur yang digunakan adalah career decision scale (CDS). Pada alat ukur CDS terdapat 2 dimensi dengan total 19 pernyataan. Dimensi dalam career decision scale yaitu (a) certaint, yang terdiri dari 3 pernyataan, dan (b) indecision, yang terdiri dari 16 pernyataan. Alat ukur ini diadaptasi dari Osipow (dalam Brown, 2012) digunakan untuk mengukur kemampuan individu dalam membuat pengambilan keputusan mengenai kariernya.

Proses penelitian diawali dengan proses try out alat ukur CDS terhadap 66 partisipan $(\mathrm{N}=66)$ di MAN B Jakarta. Uji reliabilitas menghasilkan skor a (Alpha Cronbach $)=.822$.

Pada alat ukur asli career decision scale (CDS) memiliki koefisien reliabilitas sebesar .88 (Osipow, 1981). Dengan skor reliabilitas yang baik maka perhitungan selanjutnya menggunakan skor total dari 19 item.

\section{Hasil Penelitian dan Pembahasan}

\section{Hasil Penelitian}

Sebelum dilakukan uji $t$ antara keputusan pilihan karier siswa kelas XII jurusan IPA dan IPS, maka dilakukan uji normalitas terlebih dahulu untuk mengetahui data yang diperoleh sebarannya normal atau tidak, dengan menggunakan 1-sample $K S$. Dari hasil uji normalitas diketahui bahwa sebaran data tidak normal $\mathrm{p}=.013$ $(\mathrm{p}<.05)$.

Sebaran data yang diperoleh tidak normal sehingga untuk pengujian selanjutnya digunakan teknik analisis nonparametrik Mann-Whitney. 
Tabel 2

Hasil Uji Nonparametrik Mann-Whitney

\begin{tabular}{lc}
\hline & Keputusan Pilihan Karier \\
\hline Mann-Whitney U & 3695.000 \\
Wilcoxon W & 8160.000 \\
Z & -1.940 \\
Asymp. Sig. (2-tailed) & .052 \\
\hline
\end{tabular}

Dari tabel 2 dapat diketahui bahwa dari uji Mann-Whitney diperoleh hasil $\mathrm{Z}=$ 1.940 dan $p=.052>.05$, sehingga dapat disimpulkan bahwa tidak ada perbedaan yang signifikan dari keputusan pemilihan karier siswa kelas XII jurusan IPA dan IPS.

Tabel 3

Perbandingan Skor Siswa Jurusan IPA dan IPS

\begin{tabular}{lcc}
\hline & IPA & IPS \\
\hline Mean & 40.09 & 42.28 \\
Median & 39.00 & 43.00 \\
Standar Deviasi & 8.28 & 7.37 \\
Minimum & 24 & 27 \\
Maksimum & 60 & 60 \\
Range & 36 & 33 \\
\hline
\end{tabular}

Berdasarkan tabel 3, bahwa rata-rata skor career decision scale pada siswa jurusan IPA 40.09 lebih kecil daripada ratarata skor pada siswa jurusan IPS 42.28. Pada siswa jurusan IPA skor terkecil adalah 24 dan pada jurusan IPS skor terendah adalah 27. Namun untuk skor tertinggi pada jurusan IPA maupun IPS sama-sama 60. Jarak skor tertinggi dan terendah pada siswa jurusan IPA sebesar 36 lebih tinggi daripada jarak skor tertinggi dan terendah pada siswa jurusan IPS sebesar 33 .

Tabel 4

Perbandingan Nilai pada tiap Kelas

\begin{tabular}{lcccc}
\hline & $\begin{array}{c}\text { Standar } \\
\text { Deviasi }\end{array}$ & Minimum & Maksimum & Range \\
\hline IPA 1 & 7.22029 & 27.00 & 51.00 & 24.00 \\
IPA 2 & 8.61863 & 28.00 & 56.00 & 28.00 \\
IPA 3 & 9.05449 & 24.00 & 60.00 & 36.00 \\
IPS 1 & 7.05043 & 30.00 & 59.00 & 29.00 \\
IPS 2 & 5.88894 & 27.00 & 51.00 & 24.00 \\
IPS 3 & 8.58828 & 27.00 & 60.00 & 33.00 \\
\hline
\end{tabular}

Berdasarkan tabel 4 dapat disimpulkan bahwa skor terkecil keputusan pemilihan karier siswa ada di kelas IPA 3, dan skor tertinggi keputusan pemilihan karier siswa ada di kelas IPA 3 dan juga IPS 3. Artinya bahwa siswa yang sangat yakin dengan keputusan kariernya adalah siswa yang ada di kelas IPA 3. Dan siswa yang paling bimbang dengan keputusan kariernya ada di kelas IPA 3 dan IPS 3. Jadi dapat disimpulkan bahwa di kelas IPA 3 ada siswa yang sangat bimbang dengan keputusan kariernya dan ada siswa yang sudah yakin dengan keputusan pilihan kariernya.

Dari data tersebut juga dapat disimpulkan bahwa jarak paling besar antara skor terkecil dan tertinggi keputusan pemilihan kariernya ada di kelas IPA 3 yaitu 36.00. Sedangkan jarak terkecil perbedaan antara skor terkecil dan skor tertinggi keputusan pemilihan kariernya ada di kelas IPA 1 dan IPS 2. Sedangkan standar deviasi di kelas IPS 2 pun paling kecil yaitu 5.89.

Dari olah data yang dilakukan diperoleh bahwa dari 188 siswa kelas XII, 49 siswa dengan kategori tinggi sekali artinya ada 49 siswa yang sangat bimbang dengan keputusan pemilihan karier mereka, 33 siswa dengan kategori tinggi artinya ada 33 siswa yang bimbang dengan keputusan karier mereka, 48 siswa dengan kategori sedang artinya ada 48 siswa yang cukup bimbang dengan keputusan pemilihan karier mereka, dan 48 siswa dengan kategori rendah artinya hanya ada 48 siswa yang sudah yakin dengan keputusan pemilihan karier mereka. Rincian jumlah tersebut dapat dilihat pada tabel 5. Kriteria kategorisasi menggunakan quartiles 25, 50 dan 75 .

Tabel 5

Perbadingan Kategori Keputusan Pemilihan Karier

\begin{tabular}{lcc}
\hline \multicolumn{1}{c}{ Kategori } & IPA & IPS \\
\hline Tinggi Sekali & 22 & 27 \\
Tinggi & 17 & 26 \\
Sedang & 24 & 24 \\
Rendah & 31 & 17 \\
Total & 94 & 94 \\
\hline
\end{tabular}


Berdasarkan tabel 5 dapat diketahui bahwa terdapat 22 siswa di jurusan IPA dengan skor tinggi sekali artinya ada 22 siswa di jurusan IPA yang masih sangat bimbang dengan keputusan pemilihan kariernya. Sedangkan pada jurusan IPS kategori tinggi sekali lebih banyak daripada jurusan IPA yaitu 27 siswa artinya di jurusan IPS ada 27 siswa yang sangat bimbang dengan keputusan pemilihan kariernya.

Pada kategori tinggi terdapat 17 siswa pada jurusan IPA dan 26 pada jurusan IPS. Artinya bahwa ada 17 siswa di jurusan IPA yang masih bimbang dengan keputusan pemilihan kariernya dan 26 siswa di jurusan IPS yang bimbang dengan keputusan karier mereka. Sedangkan, pada kategori sedang pada jurusan IPA dan IPS sebanding jumlahnya yaitu 24 siswa artinya bahwa pada siswa jurusan IPA ada 24 siswa yang cukup yakin dengan keputusan pemilihan kariernya begitupun di jurusan IPS.

Pada kategori rendah siswa jurusan IPA ada 31 siswa sedangkan pada siswa jurusan IPS hanya 17 siswa. Artinya bahwa siswa jurusan IPA ada 31 siswa yang sudah yakin dengan keputusan pemilihan karier mereka dan jumlah itu lebih banyak daripada jumlah siswa yang sudah yakin dengan pilihannya pada siswa jurusan IPS yang hanya berjumlah 17 siswa.

Dari hasil tersebut dapat disimpulkan bahwa kategori tinggi sekali dan tinggi pada siswa jurusan IPS lebih banyak daripada pada siswa jurusan IPA. Hal ini menunjukkan bahwa pada siswa jurusan IPS masih banyak siswa yang bimbang dengan keputusan pemilihan karier mereka. Dengan kata lain siswa jurusan IPA lebih baik dalam keputusan pemilihan karier mereka.

\section{Pembahasan}

Dari hasil penelitian yang diperoleh bahwa tidak ada perbedaan yang signifikan antara keputusan pemilihan karier pada siswa jurusan IPA dan IPS. Namun dari hasil tersebut diperoleh perbandingan bahwa siswa jurusan IPS dengan kategori tinggi sekali lebih banyak daripada siswa jurusan IPA artinya bahwa di jurusan IPS lebih banyak siswa yang masih bimbang dengan keputusan pemilihan kariernya, karena pada alat ukur CDS semakin tinggi skor menunjukkan bahwa siswa semakin bimbang dengan keputusan pemilihan kariernya. Sebaliknya semakin rendah skor menunjukkan bahwa siswa lebih yakin dengan keputusan kariernya. Begitupun dengan skor terendah lebih banyak pada siswa jurusan IPA daripada siswa jurusan IPS. Dapat disimpulkan bahwa pada siswa jurusan IPA lebih sedikit jumlah siswa yang sangat bimbang dengan keputusan pemilihan kariernya daripada siswa jurusan IPS, dan pada siswa jurusan IPA lebih banyak siswa yang yakin dengan keputusan pemilihan kariernya daripada siswa jurusan IPS.

Hasil penelitian tersebut menjawab hipotesis dalam penelitian ini bahwa siswa jurusan IPA lebih baik dalam keputusan pemilihan karier daripada siswa jurusan IPS.

Proses penempatan awal dalam penjurusan yang tidak sesuai dengan harapan siswa pada jurusan IPS karena mereka harus ditempatkan di jurusan IPS berkaitan dengan faktor nilai yang kurang mencukupi untuk masuk jurusan IPA merupakan salah satu penyebab siswa jurusan IPS lebih bimbang ke depannya untuk menentukan pilihan jurusan di perguruan tinggi. Hal ini sejalan dengan penelitian yang dilakukan oleh Aqmarina dkk. (2017) bahwa salah satu sebab kebimbangan siswa menentukan keputusan pemilihan karier mereka yaitu jurusan yang ditekuni sekarang berbeda dengan jurusan yang akan dipilih di perguruan tinggi.

Penelitian lainya juga memperkuat hasil dalam penelitian ini yang menunjukkan bahwa ada beberapa faktor yang juga ikut menentukan pemilihan keputusan yang dilakukan oleh siswa, terutama berkaitan dengan reputasi jurusan 
yang diambil, pengalaman yang banyak, serta berbagai fasilitas terkait yang disediakan dalam jurusan tersebut (Rudd, Djafarova, \& Waring, 2012). Hal tersebut juga sangat dipengaruhi oleh kondisi dan latar belakang siswa atau dalam hal ini adalah orang tua siswa dalam menentukan karier mereka (Burford dkk., 2018). Dengan demikian, ketika siswa dengan pilihan karier yang tepat digambarkan sebagai siswa yang mempunyai konsep diri yang tinggi (Krannich, Goetz, Lipnevich, Bieg, Roos, Becker, \& Morger, 2018).

Dari hasil analisa juga didapatkan penjelasan bahwa 92 siswa berada pada kategori tinggi dan tinggi sekali sedangkan untuk kategori rendah dan sedang berjumlah 96 siswa. Artinya hampir separuh dari jumlah subjek masih mengalami kebimbangan dalam keputusan pemilihan karier. Sejalan dengan penelitian yang dilakukan oleh Creed dkk. (2009) bahwa kurangnya informasi mengenai dunia kerja serta wawasan yang minim tentang program studi di perguruan tinggi merupakan suatu kendala yang menyebabkan siswa kesulitan dalam membuat keputusan karier mereka.

\section{Simpulan dan Saran}

\section{Simpulan}

Penelitian ini bertujuan untuk membandingkan keputusan pemilihan karier siswa kelas XII jurusan IPA dan IPS. Berdasarkan analisa dan olah data yang sudah dilakukan didapatkan hasil yang menjawab hipotesis bahwa tidak ada perbedaan yang signifikan antara keputusan pemilihan karier siswa kelas XII jurusan IPA dan IPS. Namun terdapat perbedaan jumlah siswa dari kategorisasi tinggi sekali, tinggi, sedang dan rendah pada siswa jurusan IPA dan IPS.

Pada siswa jurusan IPS lebih banyak jumlah siswa pada tingkat tinggi sekali dan tinggi daripada pada siswa jurusan IPA. Pada siswa jurusan IPS jumlah siswa kategori tinggi sekali dan tinggi sebanyak 53 siswa sedangkan pada siswa jurusan IPA sebanyak 39 siswa. Perbedaan ini menunjukkan bahwa siswa jurusan IPS lebih bimbang dalam menentukan keputusan pemilihan kariernya daripada siswa jurusan IPA.

\section{Saran}

Saran praktis. Terdapat beberapa saran praktis yaitu bagi pihak-pihak yang terkait dalam penelitian ini antara lain: (a) bagi siswa, bercerita kepada guru bimbingan konseling untuk dibimbing mengidentifikasi kebimbangannya dalam memutuskan pilihan kariernya, kemudian siswa dapat melakukan tes minat bakat agar mengetahui potensi dan minatnya pada bidang apa, serta meningkatkan wawasan mengenai macam-macam jurusan di perguruan tinggi dengan bertanya kepada para alumni, guru, kunjungan ke kampus (expo kampus-kampus) atau searching informasi di internet; (b) bagi orang tua, orang tua dapat mengajak anak berdiskusi dan membantu memberikan wawasan pengetahuan mengenai macam jurusan yang ada di perguruan tinggi serta beragam lapangan pekerjaan yang dapat ditekuni setelah lulus kuliah, dan (c) bagi guru bimbingan konseling maupun guru bidang studi, disarankan juga untuk membantu siswa dengan memberikan banyak informasi dan wawasan mengenai macam jurusan yang ada di perguruan tinggi dan macam dunia kerja serta membuat persiapan perencanaan karier yang lebih sistematis agar saat siswa harus memilih jurusan di perguruan tinggi mereka telah mampu mengambil keputusan itu dengan mantap dan keyakinan yang kuat terhadap pilihan yang sudah mereka putuskan berdasarkan data, pertimbangan dan wawasan yang lengkap

Saran untuk penelitian selanjutnya. Bagi penelitian selanjutnya dapat pula diteliti lebih lanjut mengenai proses pembimbingan yang telah dilakukan selama ini oleh guru bimbingan konseling sehingga dapat ditarik keterkaitan antara sebab kebimbangan siswa dalam keputusan 
pemilihan kariernya dengan cara pembimbingan yang selama ini telah dilakukan guru di sekolah. Setelah mendapatkan data itu, dapat dibuat penelitian selanjutnya mengenai rancangan program dan model program pendidikan karier bagi siswa sekolah menengah atas. Peneliti juga menyarankan agar pada penelitian selanjutnya dapat membandingkan keputusan pilihan karier siswa antara siswa SMA dengan siswa MAN.

\section{Daftar Pustaka}

Allolayuk, Y. R., Setiawan, T. I., \& Dimyati, M. (2013). Faktor yang mempengaruhi siswa memilih jurusan IPA pada siswa kelas XI SMA Negeri 72 Jakarta. Jurnal Bimbingan dan Konseling, 2(2), 14-19.

Aria, N. (2011). Faktor-faktor yang memengaruhi minat memilih jurusan IPS pada siswa kelas XI SMA Negeri 1 Juwana Kabupaten Pati tahun ajaran 2010/2011 (Skripsi tidak diterbitkan). Universitas Negeri Semarang.

Aqmarina, F. N., Sahrani, R., \& Hastuti, R. (2017). Konseling karier dengan menggunakan career informationprocessing model untuk membantu career decision-making. Psympathic, $4(1)$, doi.org/10.15575/psy.v4i1.1265

Bloxom, J. M., Bernes, K. B., Magnusson, K. C., Gunn, T. T., Bardick, A. D., Orr, D. T., \& Mcknight, K. M. (2008). Grade 12 student career needs and perceptions of the effectiveness of career development services within high schools. Canadian Journal of Counselling, 42(2), 79-101.

Brown, D. (2012). Career information, career counseling, and career development (10th ed.). Boston: Chapel Hill.

Burford, C., Hanrahan, J., Ansaripour, A., Smith, B., Sysum, K., Rajwani, K., ... Zebian, B. (2018). Factors influencing medical student interest in a career in neurosurgery. World Neurosurgery, (year 1 ), 1-8. doi.org/10.1016/j.wneu.2018.10.056

Creed, P. A., Wong, O. Y., \& Hood, M. (2009). Career decision-making, career barriers and occupational aspirations in Chinese adolescents. International Journal for Educational and Vocational Guidance, 9(3), 189203. doi.org/10.1007/s10775-0099165-0

Isaacson, L. E., \& Brown, D. (1997). Career information, career counseling, and career development (6th ed.). Boston: Allyn \& Bacon.

Krannich, M., Goetz, T., Lipnevich, A. A., Bieg, M., Roos, A. L., Becker, E. S., \& Morger, V. (2018). Being over- or underchallenged in class: Effects on students' career aspirations via academic self-concept and boredom. Learning and Individual Differences, (100014), $1-13$. doi.org/10.1016/j.lindif.2018.10.004

Osipow, S., Carney, C., Winer, J., Yanico, B., \& Koschier, M. (1987). The career decision scale: A test of concurrent validity. Psychological Reports, 759761.

Papalia, D. E., Olds, S. W., \& Feldman, R. D. (2015). Human development (10th ed.). New York: McGraw Hill.

Patton, W., \& McMahon, M. (2014). Career development and system theory: Contacting theory, and practice (3rd ed.). Boston: Sense.

Pratiwi, E. Y. (2016). Perbedaan sikap dan pola pikir siswa kelas XI IPS dengan siswa kelas XI IPA pada mata pelajaran PKn di SMA Negeri 1 Seputih Banyak Kabupaten Lampung Tengah tahun pelajaran 2015/2016 (Skripsi tidak diterbitkan). Universitas Lampung.

Rudd, B., Djafarova, E., \& Waring, T. (2012). Chinese students' decisionmaking process: A case of a business school in the UK. International Journal of Management Education, 10(2), 129-138. 
doi.org/10.1016/j.ijme.2012.04.001

Santrock, J. W. (2014). Adolescence: Perkembangan remaja (edisi ke-7). Jakarta: Penerbit Erlangga.

Santrock, J. W. (2011). Educational psychology (5th ed.). New York: McGraw Hill.

Seligman, L. (1994). Development career counseling and assesment (2nd ed.). Thousanh Oaks: Sage.
Soejono, T. (1990). Perencanaan strategi salah satu dimensi dalam pengambilan keputusan. Bandung: Angkasa.

Sugiyono. (2018) Metode penelitian kuantitatif, kualitatif dan $R \& D$. Bandung: IKAPI.

Zunker, G. V. (2012). Career counseling a holistic approach. Canada: Macmilan. 
Psympathic, Jurnal Ilmiah Psikologi Desember 2018, Vol. 5, No. 2, Hal. : 231-240 